\title{
El diseño y la educación pública
}

\section{Resumen}

Desde su reconocimiento académico y profesional en el país, ocurrido a fines de la década de 1960 como parte del proceso de reforma universitaria, el diseño pudo instalar su enseñanza a nivel de los estudios de carácter técnico o profesional en universidades, institutos profesionales y centros de formación técnica, mas no así en la educación de nivel básico o secundario en las escuelas, liceos o colegios, lugar que en cambio fue ocupado por asignaturas como dibujo, artes plásticas o técnico manual durante la mayor parte del siglo XX y por educación tecnológica desde fines del mismo.

Este artículo invita a revisar el rol que el diseño puede desempeñar a futuro en los distintos niveles de la educación pública, para aportar tanto al desarrollo de su propio quehacer como al de las disciplinas afines a las industrias creativas en el escenario de la sociedad del conocimiento.

Palabras clave: diseño, educación pública,

Más que una actividad integral, una actividad integradora Desde los comienzos de esta actividad en el país su dimensión técnica no siempre ha tenido una clara diferenciación respecto a su dimensión profesional, y esta última no necesariamente comprende una dimensión universitaria. Mientras los dos primeros ámbitos educativos han operado principalmente bajo un sentido instructivo, lo segundo comprende un sentido formativo que más allá de entregar herramientas para un escenario o contingencia determinada consiste en proponer una visión o enfoque como esfera del conocimiento que además de enfrentar escenarios actuales pueda proyectar escenarios futuros, así también contribuir al desarrollo del saber en su ámbito, tareas propias de la academia que el día a día del mundo técnicoprofesional no tiene por qué afrontar. Dicho de otra manera, si el presente es dominio mayoritario del mundo empresarial o privado, en el ámbito del diseño el pasado, presente y futuro deben ser preocupación permanente del mundo universitario en cuanto proyección 
constante de su actividad, sin olvidar que el presente resulta lo más próximo dentro de su radio de posibilidades, pero que no puede ponderarse en igual medida a los encargos o supuestos respecto a los proyectos con plazos, clientes, necesidades y recursos "reales" que están más allá de las aulas o facultades. Frente a esto, el mundo público y social debe tener una atención preferente por parte de la universidad en cuanto la baja disponibilidad de recursos económicos para el diseño en estas esferas puede ser contrarrestada con la alta disponibilidad de recursos humanos que ofrece el mundo académico.

Por otra parte, en los últimos años hemos sido testigos de cómo el enfoque general-específico en el diseño ha demandado una revisión tanto de su "profundidad de campo" en cuanto a sus conocimientos generales e igualmente de sus "focos", entendido esto como los conocimientos específicos identificados con esta actividad ${ }^{\left({ }^{(}\right)}$. Mientras lo primero suele estar asociado a la observación, análisis, estudio de casos y en definitiva con los procesos, métodos y labor investigativa en el área (el saber), lo segundo suele estar asociado a los productos, resultados o expresiones tangibles de esta actividad (el hacer). Sin embargo, la sociedad del conocimiento ha propiciado un nuevo énfasis en los intangibles y esto implica pensar más detenidamente en nociones como la propiedad intelectual o industrial, donde $\sin$ ir más lejos el ámbito de los servicios ha cobrado tanta o mayor relevancia que el ámbito de los productos, tradicionalmente identificado con el diseño desde sus orígenes mediante la producción de objetos o artefactos que en mayor o menor grado pasaron a integrar la cultura material a nivel global y local.

De acuerdo a lo anterior, la dimensión integradora del diseño está asociada a su capacidad de vincular entre sí a saberes distintos más que aspirar a la construcción de un saber propio y cerrado; el diseño es por esencia inclusivo en cuanto al conocimiento, aunque el lado más suntuario de esta actividad sea asociado en forma recurrente a un sentido exclusivo que más bien opera en el ámbito de los bienes de consumo.

\section{Más que una disciplina, una interdisciplina}

Si hacemos la analogía entre una ciudad y el conocimiento humano, los saberes más reconocibles o tradicionales se localizan en las cuadras de esta ciudad, mientras el diseño, dada su juventud y su carácter dinámico, más bien se sitúa en las calles como un territorio abierto, público, cuya misión es justamente producir nuevos vínculos entre distintas disciplinas, reconociendo los diferentes ámbitos del conocimiento humano, identificando las redes preexistentes y vislumbrando las redes futuras posibles de construir. En tal sentido, la labor a desempeñar por el diseño tiene un rol fundamental que cumplir en cuanto a los procesos de transferencia de contenidos, dado que su labor creativa puede trasladar conceptos o procesos de un ámbito del conocimiento a otro, contribuyendo tanto a la solución de problemas como a la detección de oportunidades mediante la construcción permanente de una red de "vasos comunicantes" en el mundo contemporáneo.

Tras la etapa de legitimación profesional y universitaria, situada entre las décadas de los 70 y los 90 , el ensimismamiento profesional que afectó a gran parte de las escuelas de diseño en el país alejó a su enseñanza de un sentido interdisciplinario que pudo reportarle mayores y mejores frutos; de acuerdo a lo sucedido en distintos contextos históricos clave para el desarrollo de esta actividad en el mundo, como la sociedad inglesa de mediados del siglo XIX, la alemana de comienzos y mediados del siglo XX o la estadounidense de la posguerra, el cruce de saberes de distinta procedencia siempre tuvo consecuencias favorables para el diseño y al respecto el mundo universitario puede y debe ser el lugar por excelencia para esto, aunque ello no siempre ocurra.

\section{El fomento de las industrias culturales y creativas desde} la enseñanza universitaria

Acorde al carácter proyectual que atañe al diseño desde su legitimación como ámbito del conocimiento, una de las premisas centrales de esta actividad en la educación pública de nivel superior debe ser el reconocimiento de escenarios pasados o actuales en razón de visualizar escenarios futuros o posibles, esto mediante la elaboración permanente de enfoques, conos de visión o acercamientos, expresados gráficamente en la construcción de mapas que representen dichos escenarios con sus correspondientes actores y las interacciones entre ellos. En cuanto a los actores, éstos pueden ser personas o instituciones, donde en el primer caso puede tratarse de individuos o de pequeños grupos que jueguen un rol en cuanto informantes clave, mientras en el segundo caso puede tratarse de instituciones pertenecientes al ámbito público, privado o social. Lo importante en este ejercicio es que lejos de cualquier afán por delimitar un campo determinado resulta de mayor importancia visualizar la forma de expansión de dicho campo, así también los circuitos o redes posibles en torno a un determinado proyecto.

En cuanto a la presencia del diseño como actividad económica capaz de aportar al desarrollo de un país éste puede ser considerado dentro de la industria cultural ${ }^{(2)}$; sin embargo, una 
definición reciente a la que ha sido asociado es la de las industrias creativas ${ }^{(3)}$, en cuanto éstas incluyen no sólo a los medios de comunicación masiva o a las obras afectas a derechos de autor, sino que además pueden involucrar la labor del diseño en un sentido amplio, considerando tanto la producción a pequeña o mediana escala, los bienes materiales o inmateriales y el ámbito de los productos o los servicios, al tiempo que no solo hablamos de actividades de orden artístico o comunicacional, sino que también consideramos al quehacer más cercano a disciplinas de carácter científico-tecnológico ${ }^{(4)}$ La formación de recursos humanos en las distintas direcciones antes enunciadas puede encontrar un aliado importante en el diseño mediante el trabajo constante en torno a los siguientes tópicos: conceptos; tecnologías; lenguajes; referentes; disciplinas; problemas.

- En cuanto a los conceptos, esto hace alusión a las definiciones básicas, las ideas fuerza o las nociones elementales que guían un proyecto determinado.

- $\mathrm{Al}$ referirnos a las tecnologías, abordamos tanto los procesos productivos que permiten la elaboración de productos o servicios en el mundo de hoy, como los medios que permiten la comunicación de los mismos.

- En lo que respecta a los lenguajes, nos referimos al idioma para transmitir un determinado contenido, pudiendo ser éste de orden escrito, visual, audiovisual, sonoro, entre otros.

- Al hablar de los referentes, aludimos a elementos de orden cultural ya presentes o establecidos, que constituyen lo que llamamos la "parentela" del proyecto, en cuanto un ejercicio de calce-descalce respecto a éstos permite visualizar qué nos acerca o asocia con dichos referentes y qué nos aleja o distingue de los mismos.

- Al señalar las disciplinas, intentamos ir al reconocimiento de los distintos ámbitos del conocimiento humano cuya presencia sea posible de identificar en el contexto de un proyecto.

- Al considerar los problemas, incluimos la observación crítica de las necesidades, conflictos o dificultades del mundo contemporáneo, donde más que "salvar el mundo" lo que se busca es promover tanto una visión crítica como la detección de oportunidades.

El trabajo constante en torno a los seis ámbitos antes señalados, comprende en un sentido vertical el acopio de datos en cuanto a cada uno a la manera de un "estado del arte", reservando al proyecto la perspectiva horizontal entre dichas columnas de información, donde un concepto o idea fuerza sumado al interés por tecnologías determinadas, la expresión otorgada por uno o más lenguajes, las coordenadas o luces aportadas por distintos referentes, el énfasis señalado por ciertas disciplinas y finalmente el valor ético de considerar alguna problemática del mundo actual, puede traducirse en diferentes proyectos de diseño cuya escala sea apropiada a las distintas etapas de la formación, así también a los recursos humanos, técnicos y económicos disponibles.

Acorde al desarrollo del diseño en el mundo, durante el siglo XIX la discusión entre arte y técnica fue clave para el reconocimiento de esta actividad ${ }^{(s)}$ en el escenario de la revolución industrial, lo que a nivel de la enseñanza encontró su correlato en la educación artística y la educación tecnológica; la primera identificada con la tradición de las bellas artes ${ }^{(6)}$ y la segunda con la de las artes y oficios ${ }^{(7)}$. Sin embargo, la transición al siglo XX asignó importancia a otras acepciones como las artes decorativas ${ }^{(8)}$ y las artes aplicadas ${ }^{(9)}$,que representaron una expresión más clara del debate entre arte y técnica, así también de los desafíos de la industrialización y su expansión a la vida cotidiana. Pero el avance de este siglo trajo consigo otros polos de influencia para el diseño, y en el escenario más reciente tanto las comunicaciones, las ciencias sociales y la economía han hecho sentir su impacto en este quehacer ${ }^{\text {(10) }}$.

Nos hemos referido aquí a la enseñanza universitaria en cuanto su dimensión formativa aspira a este diálogo entre el saber y el hacer, mientras la enseñanza técnica reconoce mayor énfasis en lo segundo y en el caso de la enseñanza profesional la producción del conocimiento no es lo relevante sino la acreditación de competencias ${ }^{(11)}$. La educación pública de nivel superior es un escenario inmejorable para la formación en diseño dada la posibilidad de interactuar con distintas disciplinas afines, así también de realizar un aporte al conocimiento y a la cultura del país mediante las funciones de investigación, extensión y creación que son inherentes al mundo universitario, además de la docencia.

La educación tecnológica en la enseñanza básica y secundaria Esta línea de contenidos dentro de la educación básica y secundaria chilena por años estuvo asociada a una asignatura de carácter obligatorio (artes plásticas) y otra de orden obligatorio/electivo (técnico manual); lo primero vinculado al sentido del "arte" y lo segundo al del "oficio". Sin embargo, la alianza más fructífera entre "artes y oficios" realmente no se produjo en Chile, debido a que la educación artística orientada a fines prácticos y la educación tecnológica construyeron sus propios espacios que sin embargo no coincidieron en un amplio sentido; respectivamente, aludimos a la Escuela de Artes Aplicadas en el caso de la Universidad de Chile (1928-1968) y a la Escuela de Artes y Oficios (1849-1976) ${ }^{(\mathrm{r} 2)}$, plantel que dio origen posteriormen- 
te a la Universidad Técnica del Estado ${ }^{(13)}$.Por esto resulta importante que los primeros pasos para el diseño propiamente tal en el país hayan sido justamente en la sede Valparaíso de la Universidad de Chile, en una Facultad que llevó justamente el nombre de "Arte y Tecnología", en los años previos a la reforma universitaria de fines de los años 60 .

Con el advenimiento del modelo neoliberal y el ocaso del anhelo industrialista propio de los años del "desarrollo hacia adentro", estos contenidos perdieron fuerza al interior de las escuelas, colegios y liceos justamente a causa del declive del paradigma industrial, lo que restó importancia a la enseñanza de los oficios en los niveles básico y secundario ${ }^{(14)}$, mientras que en el caso de las artes plásticas el ascenso de las nuevas tecnologías de la información y comunicación fue un escenario que mermó a nivel de la enseñanza pública el cultivo de la formación artística en vez de potenciarla; esto último, principalmente porque en lugar de compatibilizar el legado de las bellas artes con el acceso a los nuevos medios, la brecha digital entre profesores y alumnos, así también la escasa disponibilidad de recursos tecnológicos en los establecimientos (no así a nivel de los estudiantes en sus hogares), tendió a producir una separación de mundos entre estos lenguajes análogos y digitales en lugar de aprovechar las oportunidades que el cruce de los mismos ofrecía.

Frente a esta coyuntura, el diseño puede tener un rol central en la educación tecnológica del país y desde su sentido interdisciplinario aportar un nuevo impulso al desarrollo del curriculum para educación básica y secundaria. Si en los primeros tiempos de la enseñanza artística en Chile maestros visionarios como el pintor Juan Francisco González promovieron la importancia del dibujo y su enseñanza en cuanto lenguaje y herramienta que posibilitaba ver con claridad yendo así a la comprensión profunda del sentido del arte y su lenguaje como expresión de la creatividad humana, hoy el diseño tiene un rol central en el trazado mental de mapas que permitan reconocer tanto los caminos actuales del saber humano en los ámbitos científico-tecnológico, artístico o de las comunicaciones, como en la visualización de nuevos caminos posibles a través del cruce de saberes. Recordando lo señalado en el segundo punto, hablamos del reconocimiento de redes existentes y de ir al descubrimiento de redes nuevas.

De acuerdo a lo antes expuesto, la perspectiva del diseño puede transformar a la asignatura de educación tecnológica en un crisol de proyectos, escalado según los distintos niveles en los que se imparte. Esto busca que más allá del estado actual de esta enseñanza, donde los docentes deben hacer de "profesores orquesta" en cuanto a contenidos donde se mezcla el oficio manual con Internet o los trabajos de investigación, sea el alumno el responsable del gran barrido de antecedentes, reservando al docente la misión de aportar a los estudiantes en cuanto a la construcción de una mirada transversal de las columnas de información señaladas en el punto anterior. Y entendiendo que la asignatura debe propiciar el surgimiento de resultados medibles, éstos pueden ser proyectos de investigación o creación, en cuanto lo primero significa la generación de conocimiento en formato escrito combinado a otros lenguajes (visual, audiovisual, etc.), mientras lo segundo comprende el desarrollo de una obra material o inmaterial que permita expresar un punto de vista o enfoque. Se trata de que el hacer sea necesariamente la expresión visible del conocimiento, más que un oficio irreflexivo sin preguntas de fondo.

\section{Premisas finales}

El presente texto surge a raíz de las movilizaciones por la educación pública que han marcado la agenda nacional de Chile en el tiempo reciente, pues justamente el diseño ha sido una de las carreras que vivió la hipertrofia de los años exitosos del modelo neoliberal en educación, donde la matrícula anual y el llenado de vacantes fueron por mucho tiempo la preocupación principal -si no la única-, descuidando la docencia y prestando escasa o nula atención a las restantes funciones de investigación, creación y extensión que forman parte de la misión universitaria. Sin embargo, la visión más tradicional de esta formación ${ }^{(15)}$ ha entrado en crisis debido al excesivo aumento de los recursos humanos en razón de un medio donde las oportunidades de desarrollo profesional se han estrechado mientras que las de desarrollo académico se han ampliado ${ }^{(16)}$, lo que demanda un compromiso aún mayor por parte del mundo universitario en erigir nuevos espacios y opciones para el diseño en el medio local, en vez de continuar pensando sólo en los lugares existentes a la fecha. En este sentido, impartir su enseñanza a lo largo de todos los niveles de la educación pública puede ser un paso importante hacia un mayor y mejor aporte de esta actividad al desarrollo del país, así también a la cultura y a la calidad de vida de sus ciudadanos, canalizado esto mediante la formación de nuevos profesionales cuyo paso por la educación superior no requiera de conocimientos que perfectamente pueden ser adquiridos en la educación básica y secundaria, lo que permitiría elevar el nivel académico del diseño en el mundo universitario, al tiempo que su presencia en la educación pública a nivel de escuelas, colegios y liceos puede aportar igualmente al desarrollo posterior de estudiantes que opten por una formación en el ámbito científico-tecnológico, artístico o de las comunicaciones ${ }^{(17)}$, todos de gran importancia para el desarrollo de las industrias culturales y creativas. 
1. Entre éstos, podemos mencionar al diseño de información, diseño tipográfico, diseño editorial, diseño web, diseño de vestuario, diseño de identidad, por nombrar algunos.

2. Término utilizado desde mediados del siglo XX para referirse a la producción editorial, cinematográfica, audiovisual, musical, radial, que transmite expresiones de carácter cultural en forma independiente a su dimensión comercial.

3. Esta definición reciente proviene de Inglaterra donde en 1998 fue reconocida dentro del Department of Culture, Media and Sport. Si bien incluye a la industria cultural, se distingue de esta acepción previa en cuanto las industrias creativas utilizan la cultura como contenido que adquiere forma a través de una producción funcional. Es el caso del interés reciente del diseño por el ámbito patrimonial. A nivel internacional, un reconocimiento clave para el diseño en tal sentido es la publicación en abril de 2010 del Libro verde de las industrias culturales y creativas, documento emitido por la Comunidad Europea.

4. Como puede ser el caso del diseño automotriz o el diseño de software, por nombrar algunos ámbitos específicos más próximos a la ingeniería.

5. Valga recordar la creación del Consejo de Diseño Industrial en Inglaterra el año 1838.

6. Beaux arts según la denominación francesa.

7. Acepción que tuvo distintas miradas en Europa, destacando la de las art et métiers, francesa, y el art and crafts inglés. Mientras la primera promovía el desarrollo de las artes mecánicas y el estudio de los oficios con su horizonte en el ámbito de la ingeniería, la segunda buscó afrontar los desafíos del maquinismo desencadenado por la revolución industrial, discusión que condujo posteriormente al desarrollo de las escuelas de artes aplicadas en el paso del siglo XIX al XX, que fueron un antecedente directo de las futuras escuelas de diseño en el mundo.

8. Arts decoratifs, término también de procedencia francesa, que sirvió para designar a las expresiones de la cultura material poseedoras de un valor artístico pero distintas a las bellas artes, como la cristalería, los tapices, la mueblería, la joyería entre otras. Difieren de las beaux arts en cuanto puede tratarse de piezas producidas de forma única, a pequeña escala o en serie, pero que además de un valor de signo (artístico) pueden estar asociadas a un valor de uso (funcional) al tiempo que su valor de cambio (económico) tendió a volverse menos exclusivo y más abierto al consumo en el escenario de la revolución industrial.

9. Denominación que cobró una importancia central en el marco de la reforma impulsada por el arquitecto Herman Mutesius, precursor del Deutsche Werkbund, movimiento que desde 1907 promovió una nueva alianza entre los oficios tradicionales y la producción industrial, infundiendo una visión moderna que condujo años más tarde a los cimientos del diseño en el mundo con la fundación de la Bauhaus en 1919.

10. Respectivamente, podemos asociar cada uno de estos ámbitos a dominios específicos relevantes para el diseño, como es el caso del branding, los estudios de usuario y el diseño estratégico.

11. Al respecto, valga recordar que los institutos profesionales realizan esencialmente docencia y otorgan el título que acredita la competencia en una determinada profesión, mas no contemplan grado académico (licenciatura), lo que en el caso del mundo universitario exige la producción de un documento escrito que pueda servir en adelante como fuente de consulta.

12. En el caso de este plantel, la influencia fundacional provino del modelo de Art et métiers de origen francés, en lugar del arts and crafts inglés.

13. Que pasó a conformar la Universidad de Santiago tras la ley de educación de 1981 que separó a esta institución de carácter estatal de sus distintas sedes a nivel nacional.

14. Valga considerar el claro declive experimentado a partir de los años noventa por la enseñanza técnica de carácter secundario, expresado en la precaria situación de los liceos industriales, otrora éxito de la educación pública chilena, mientras en el caso de los liceos comerciales el panorama ha sido inverso al integrar a un gran número de sus egresados al ámbito de los servicios.

15. Aludimos aquí a la dicotomía entre el diseño gráfico y el diseño industrial, como las versiones más tradicionales de esta profesión.

16. Al respecto, valga considerar el crecimiento en la oferta de educación continua en el país, el aumento en la preocupación por cursar estudios de posgrado y las opciones de becas nacionales e internacionales a las que han optado de manera creciente los profesionales del área.

17. Nos referimos aquí a carreras como arquitectura, artes visuales, periodismo, publicidad, comunicación audiovisual, cine, fotografía, ingeniería informática.

\section{Bibliografía}

Álvarez, P. (2004). Historia del diseño gráfico en Chile. Santiago, Chile: Escuela de Diseño PUC.

Bonsiepe, G. (1999). Las siete columnas del diseño: Del objeto a la interfase. Buenos Aires, Argentina: Infinito.

Castillo, E. (Ed.). (2012). La discusión sobre las artes y oficios en los albores de la república [segundo semestre]: Revista Chilena de Diseño, (2).

Castillo, E. (Ed.). (2010). Artesanos, Artistas, Artifices: La Escuela de Artes Aplicadas de la Universidad de Chile (1928-1968). Santiago, Chile: Ocho Libros Editores-Pie de Texto.

Castillo, E. (2010). Waldo González: Obra gráfica. Santiago, Chile: Ediciones UDP.

De Fusco, R. (2005). Historia del Diseño. Barcelona, España: Santa \& Cole.

Instituto Nacional de Propiedad Industrial. (2010). Historia gráfica de la propiedad industrial en Chile. Santiago, Chile: INAPI.

Margolin, V. (2005). Las rutas del diseño. Ciudad de México, México: Editorial Designio.

Read, H. (1961). Arte e Industria. Buenos Aires, Argentina: Editorial Infinito.

(s.a.). (2010).Libro verde. Liberar el potencial de las Industrias Culturales y Creativas. Bruselas, España: Comisión Europea. 